International Journal of Project Management, Volume 28, Issue 3, April 2010, Pages 245-255

\title{
Deliberate ignorance in project risk management
}

\author{
ELMAR KUTSCH \\ LECTURER IN OPERATIONS MANAGEMENT \\ LECTURER IN PROJECT AND PROGRAMME MANAGEMENT \\ SCHOOL OF MANAGEMENT \\ CRANFIELD UNIVERSITY \\ CRANFIELD \\ BEDFORDSHIRE \\ MK43 0AL \\ UNITED KINGDOM \\ TEL.: +44 (0) 1234751122 \\ FAX.: +44(0) 1234751806 \\ E-MAIL: ELMAR.KUTSCH@CRANFIELD.AC.UK
}

MARK HALL

SENIOR LECTURER

UNIVERSITY OF BRISTOL

DEPARTMENT OF MANAGEMENT

8 WOODLAND ROAD

BRISTOL

BS8 1TN 


\section{Deliberate ignorance in project risk management}

The management of project risk is considered a key discipline by most organisations involved in projects. Best practice project risk management processes are claimed to be self-evidently correct. However, project risk management involves a choice between which information is utilized and which is deemed to be irrelevant and hence excluded. Little research has been carried out to ascertain the manifestation of barriers to optimal project risk management such as 'irrelevance'; the deliberate inattention of risk actors to risk. This paper presents the results of a qualitative study of IT project managers, investigating their reasons for deeming certain known risks to be irrelevant. The results both confirm and expand on Smithson's [1] taxonomy of ignorance and uncertainty and in particular offer further context related insights into the phenomenon of 'irrelevance' in project risk management. We suggest that coping with 'irrelevance' requires defence mechanisms, the effective management of relevance as well as the setting of, and sticking to priorities.

Keywords: Project, Risk, Process, Irrelevance, Effectiveness 


\section{INTRODUCTION}

Institutions such as the Project Management Institute (PMI) and the Association of Project Management (APM) promote 'best' practice project management standards. Project risk management, as one of the key disciplines of project management, is defined as the systematic process of identifying, analysing and responding to risk as project-related events, or managerial behaviour, that is not definitely known in advance, but that has potential for adverse consequences on a project objective [2]. Project risk management claims to enable project managers to effectively manage risk related information.

Raz and Michael [3] have investigated the extent to which project managers perceived project risk management as effective. Specifically, they looked at an extensive range of risk management techniques, rating each against a 'project management performance' index based on the responses to their survey. However, such evidence is scarce, often descriptive and inchoate. In order to address some of these shortcomings, this study investigates how 'irrelevance'; the deliberate ignorance of risk related information, manifests itself in the context of project risk management and how it constrains the perceived effectiveness of project risk management. In doing so, we seek to add to the debate on the effectiveness of risk management processes by considering the influence of social and cognitive factors as intervening conditions in project risk management.

\section{BEST PRACTICE IN PROJECT RISK MANAGEMENT}

Risks potentially endanger the ability of the project manager to meet predefined project objectives of scope, time and cost. This ultimately means that tasks may take longer than planned with a negative consequence on the project manager's fulfilment of the project objectives [2]. Because of this potential to adversely influence a project's performance, the PMI acknowledges the management of risk as one of its nine key 
knowledge areas in its Guide to the Project Management Body of Knowledge [2]. According to Pender [4], this represents 'best' practice in the area of project management.

Beyond the PMI standards, there are a number of other "best practice" project risk management processes such as the British Standards Institute [5], the Office of Government Commerce [6] or the UK Association for Project Management [7]. The basic structure of all these models is similar. Table 1 gives an overview of the key elements.

Table 1: Overview of main project risk management processes

\begin{tabular}{llll}
\hline $\begin{array}{l}\text { Major steps in project risk } \\
\text { management }\end{array}$ & $\begin{array}{l}\text { PMBOK - PMI risk management process } \\
{[2]}\end{array}$ & $\begin{array}{l}\text { OGC - Management of risk } \\
{[9]}\end{array}$ & $\begin{array}{l}\text { PRAM - APM risk management process } \\
{[12]}\end{array}$ \\
\hline Planning & Risk Management Planning & Context & Focus \\
& Risk Identification & Define & Identify \\
Identification & Risk Analysis & Assess - Estimate & Estimate \\
Analysis & Assess - Evaluate & Evaluate \\
Response & Risk Response Planning & Plan & Plan \\
& & Implement & Ownership \\
\hline
\end{tabular}

Regardless of the number and definition of stages, the mentioned project risk management processes have one element in common: "an activity that deals with planning actions that will be implemented in order to reduce the exposure to risk" [8]. This principle activity can be subdivided into four major stages: planning, identification, analysis, and response. Firstly, a project manager can apply risk management planning to define what activities should be taken to approach project risks. Secondly, risk identification allows project managers to single out risks that may affect the project objectives. Thirdly, by using risk analysis a project manager evaluates quantitatively or qualitatively the likely consequences of risks as well as the likelihood of occurrence [9]. 
Fourthly, risk response helps a project manager to develop procedures and techniques to mitigate the defined risks, and enables the project manager to keep track of these, to identify new risks during the project and to implement risk response plans [2].

Best practice project management standards, as set out by the PMI and APM, indirectly claim to be self-evidently effective. In this respect, Williams [10] argues:

"Project management as set out in this work is presented as a set of procedures that are self-evidently correct: following these procedures will produce effectively managed projects; project failure is indicative of inadequate attention to the project management procedures."

Project risk management processes such as those described have their foundation in expected utility theorem (EUT) $[7,11]$. Expected utility is "a weighted average of the utilities of all the possible outcomes that could flow from a particular decision, where higher-probability outcomes count more than lower-probability outcomes in calculating the average" [12]. In other words, the utility of decision making choices are weighted by their probabilities and outcomes $[11,13]$.

EUT has generally been accepted in the literature as a model of rational choice for taking risky decisions $[11,12]$ and is considered a fruitful framework for decisionmaking in situations where risk is a factor [14]. A key feature of EUT is the presumption of rationality, or what Weber et al call 'hyper rationality' [15]. This prevailing normative and explanatory framework in decision making under uncertainty tends to ignore the absence or 'distortion' of truth. Hence, social influences are downplayed. For example, ignorance is excluded. 


\section{THE ROLE OF IGNORANCE IN PROJECT RISK MANAGEMENT}

Recently, some attention has been paid to ignorance in various contexts $[16,17]$. Research has increasingly concentrated on the pursuit of certainty and how to overcome ignorance, which is often cited as a lack of 'true' knowledge [18]. Although this definition deserves credit, developing a single definition would be inappropriate because ignorance is a multidimensional concept with various facets (see

Figure 1). In particular, a useful distinction can be made between deliberate ignorance, driven by social factors and/or conditioning, and ignorance as an affective impulse, meaning it is beyond one's control, both systemically and cognitively [19]. The concept of error including its various sub-concepts (see Table 2,

Figure 1), such as distortion, relates to the passive connotation of incomplete knowledge (being ignorant). Perfect knowledge about the future state of an environment is not possible and error will always occur despite attempts of correction through clarification and exactitude. In contrast, deliberate ignoring is defined as irrelevance that may be managed through the application of specific defence mechanisms [1]. It is not that 
information is missing or wrong (error), but rather that the presence of particular information is not deemed important by stakeholders risk in a particular context. While individuals have limited control over the extent of error, they have substantial control over the extent to which they choose to regard risk information as being irrelevant. Therefore, it is with irrelevance that we concern ourselves in this study (i.e. deliberate ignorance) rather than error.

Figure 1: Taxonomy of ignorance [1]

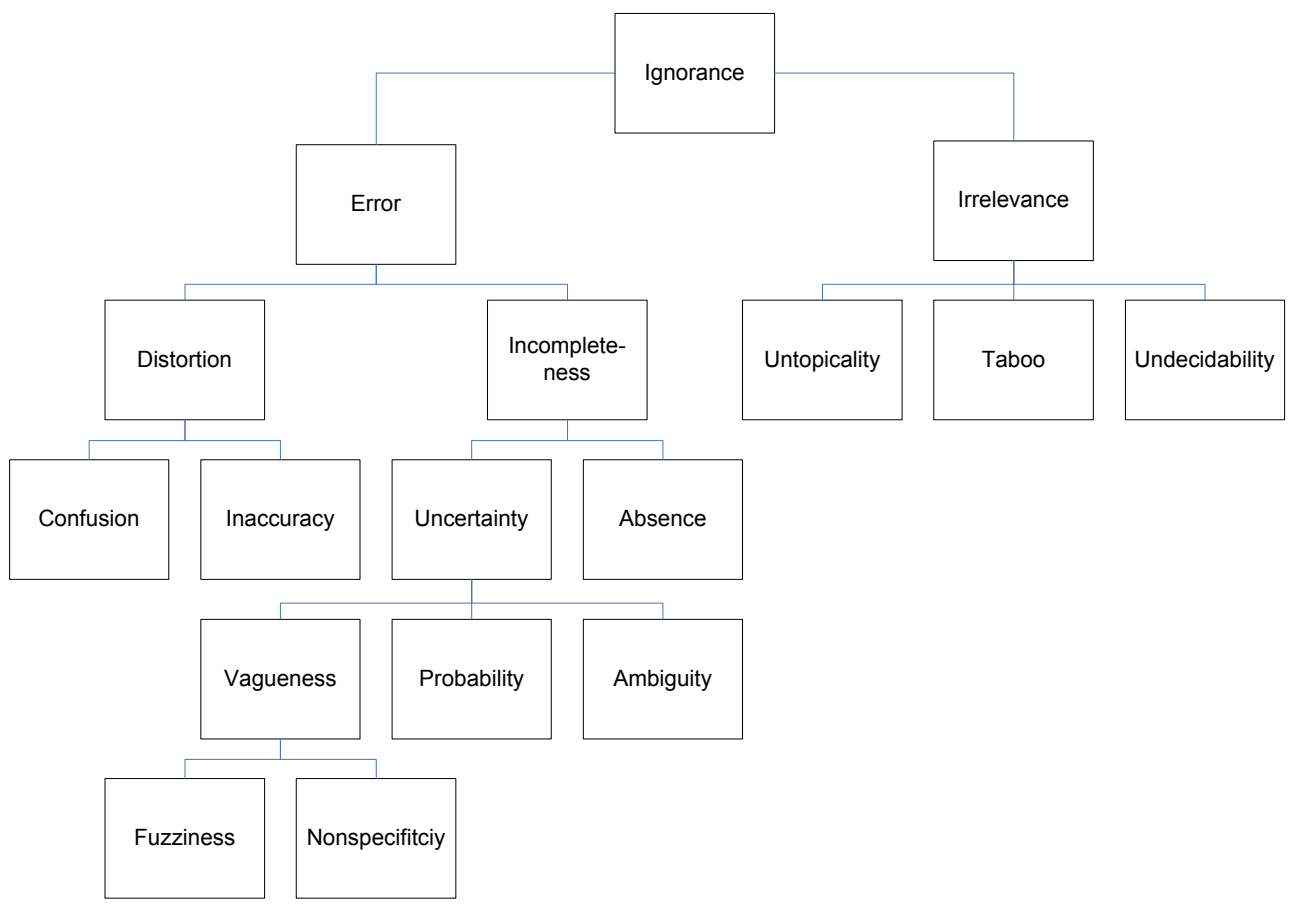

Table 2: Types of ignorance - meanings [1]

\begin{tabular}{lll}
\hline Term & Meaning \\
\hline 1. & Error & \\
1.1. & Distortion & \\
& 1.1.1. Confusion & Wrongful substitutions \\
1.1.2. Accuracy & Bias and distortion in degree \\
\hline
\end{tabular}




\begin{tabular}{|c|c|c|}
\hline \multicolumn{3}{|c|}{ 1.2. Incompleteness } \\
\hline \multicolumn{2}{|r|}{ 1.2.1.1. Vagueness } & $\begin{array}{l}\text { Non-crispness of belonging and non-belonging of } \\
\text { elements to a set or notion of interest }\end{array}$ \\
\hline \multicolumn{2}{|r|}{ 1.2.1.1.1. Fuzziness } & The quality of being indistinct \\
\hline \multicolumn{2}{|r|}{ 1.2.1.1.2. Nonspecificity } & $\begin{array}{l}\text { Failure to indicate in sufficient detail to permit } \\
\text { identification }\end{array}$ \\
\hline \multicolumn{2}{|r|}{ 1.2.1.2. Probability } & Chances of outcomes \\
\hline \multicolumn{2}{|r|}{ 1.2.1.3. Ambiguity } & $\begin{array}{l}\text { The possibility of having multi-outcomes of processes or } \\
\text { systems }\end{array}$ \\
\hline \multicolumn{2}{|r|}{ 1.2.2. Absence } & Incompleteness in kind \\
\hline \multicolumn{3}{|c|}{ Irrelevance } \\
\hline 2.1 . & Untopicality & $\begin{array}{l}\text { Intuitions of experts that could not be negotiated with } \\
\text { others in terms of cognitive relevance }\end{array}$ \\
\hline 2.2 . & Taboo & $\begin{array}{l}\text { Socially reinforced irrelevance. Issues that people must } \\
\text { not know, deal with, inquire about, or investigate }\end{array}$ \\
\hline 2.3 . & Undecidability & $\begin{array}{l}\text { Issues that can not be designated true or false because } \\
\text { they are considered insoluble, or solutions that are not } \\
\text { verifiable }\end{array}$ \\
\hline
\end{tabular}

The first, and most obvious kind of irrelevance is untopicability, referring to information that is declared 'off-topic' resulting in a limiting the range of information and risks that project managers deem pertinent to focus upon. Some literature on project risk management refers to untopicability. For example, Margolis [20] argues: “experts in general learn to concentrate on what is critical in their experience with the domain at hand and ignore anything else."

A further sub-concept is taboo. Taboos reflect a moral and/or cautionary restriction placed on action based on what is deemed inappropriate $[1,21]$. The process of project risk management requires project manager to expose risks for the purpose of analysing and responding to them. However, the exposure may also create anxiety among stakeholders, and negative thoughts may be suppressed [22]. In an extreme case, the exposure of risks may result in the cancellation of the project because stakeholders take new risks into account and decide not to go ahead with a project that is now perceived as too risky [23]. As a result, project managers may limit the degree to which they 
identify new risks. Risks, although legitimate, may then be suppressed during the risk identification phase and ultimately ignored.

The final aspect of irrelevance is undecidability. This concerns whether information is considered 'true' or 'false' [1]. Due to the lack of statistical data for predicting future risks, project managers often rely on subjective estimates [24]. However, other stakeholders may not believe in the credibility of these estimates. Hence, during the phase of risk identification and risk analysis, stakeholders might disagree [25] over which risks are considered to be 'true', with the result that some risks will be deemed as not pertinent and, as a result, are excluded from any active management.

Few studies have investigated these types of ignorance, especially in the context of project management. Although some studies have tried to address the importance of malice of project managers managing risk, most of the evidence is descriptive and relies on assumptions rather than on empirical findings [26, 27]. These findings thus lack theoretical relevance. This study aims to address the limitation by providing empirical evidence on the role of irrelevance in project risk management. As a result, in the light of the lack of previous research, this study will shed some light on whether irrelevance can be seen to manifest itself in IT project management and, if this is the case, the nature of the impact irrelevance has on risk management in IT projects?

\section{METHOD}

This study used an exploratory approach in order to understand the 'social reality' of project managers and how they experienced irrelevance in project risk management. First, the research sought to confirm that the three types of irrelevance (undecidability, taboo, untopicality) were experienced, and could be readily identified, in the everyday working life by the research participants. When the different types of irrelevance had been established, in the context of project risk management, questions were asked to 
probe their perceived impact on the effectiveness of project risk management processes that were being employed in projects where the respondents were working. A further aim of the investigation was to explore whether further types of deliberate ignorance could be identified.

Due to the exploratory nature of the study, an interpretivist research approach was adopted, employing face-to-face semi-structured interviews, guided by a topic rather than a set of specific questions. The purpose of this was to allow an in-depth insight into the lived reality of the research participants in their project environments. The population from which the sample was drawn consisted of IT project managers who were members of the PMI and the APM. For this study, non-probability sampling was applied, because it is often more beneficial "to learn a lot from an atypical case than a little from a magnificently typical case" [28]. Atypical in this study implies that cases were chosen that revealed overall extreme difficulties which IT project managers faced while managing project risks. The rationale for such a deliberative sampling method is that extreme and atypical cases tend to give more information [28] and thus allowed the phenomenon of intervening factors to become more 'visible'. The sample size in the exploratory phase of this study was determined by conceptual saturation. Saturation was reached after 18 in-depth interviews when no new information or themes about irrelevance were observed in the data. The profile of the sample in the exploratory research is shown in Table 3:

Table 3: Profile of exploratory sample

\begin{tabular}{lccccc}
\hline Company & Interviewee & Project & Position & $\begin{array}{c}\text { Approx. project } \\
\text { budget (fm) }\end{array}$ & $\begin{array}{c}\text { Project duration } \\
\text { (months) }\end{array}$ \\
\hline Company A & Interviewee 1 & Project 1 & IT project manager & 15 & 36 \\
Company B & Interviewee 2 & Project 2 & IT consultant & 5 & 18 \\
Company C & Interviewee 3 & Project 3 & IT project manager & 1 & 1 \\
Company C & Interviewee 4 & Project 4 & IT project manager & 10 & 2 \\
Company D & Interviewee 5 & Project 5 & IT project manager & 0.008 & 0.25 \\
\hline
\end{tabular}




\begin{tabular}{llllcc}
\hline Company E & Interviewee 6 & Project 6 & IT project manager & 18 & 12 \\
Company F & Interviewee 7 & Project 7 & IT project manager & 1 & 12 \\
Company G & Interviewee 8 & Project 8 & IT project manager & $30-40$ & 18 \\
Company H & Interviewee 9 & Project 9 & IT project manager & 3 & 14 \\
Company I & Interviewee 10 & Project 10 & IT project manager & 7 & 18 \\
Company J & Interviewee 11 & Project 11 & IT project manager & 10 & 18 \\
Company J & Interviewee 12 & Project 12 & IT project manager & 150 & 48 \\
Company J & Interviewee 13 & Project 13 & IT project manager & 15 & 1 \\
Company J & Interviewee 14 & Project 14 & IT project manager & 40 & 6 \\
Company J & Interviewee 15 & Project 15 & IT project manager & 100 & 6 \\
Company J & Interviewee 16 & Project 16 & IT project manager & 1000 & 120 \\
Company J & Interviewee 17 & Project 17 & IT project manager & 30 & 18 \\
Company K & Interviewee 18 & Project 18 & IT project manager & 8 & 36 \\
\hline
\end{tabular}

As can be seen in Table 3, some of the IT project managers work for the same company. However, each interview related to a different project. In this study, the specific project being discussed by the interviewees, and the interviewees themselves were independent variables. Project risk management was the dependent variable. In this study, all the interviewees were project managers, or senior members of the project team, who had responsibility for implementing the project risk management process. Clearly, these individuals had a particular, situated perspective which would differ from other project actors and stakeholders (such as project owners/sponsors). For these other project actors, the findings might well be different.

For the purpose of making sense of the qualitative data contained in the interview transcripts, a template approach [29] was applied using a proprietary qualitative data analysis software package. Some codes existed prior to the data analysis based on Smithson's taxonomy [1]. These served as main codes, within which sub codes emerged. The characteristics of the main codes changed continuously up to the stage where no data further illuminated coding (concept saturation). 


\section{FINDINGS}

Project managers were questioned about how they managed risk, whether it was effective from their point of view and what difficulties they encountered. Those highlighted difficulties that related to a deliberate inattention to risk were further explored.

\section{Untopicality}

This was first type of irrelevance that emerged during the analysis. For example, Interviewee 16 noted that project managers working in his project mainly focused on technical risk, delaminating the range of risks to be considered:

"They looked purely on the implementation and not from a technical point of view, they had not looked at it from a business point of view." (Interviewee 16)

The decision to restrict the degree of information appears to focus on the perceived ease of information processing. Risks are deemed pertinent that are actually 'easy' to identify, analyse and respond to:

"We looked for risks that were easily identifiable, but didn't actually have serious consequences for the project. The project was not really at threat from these risks.” (Interviewee 1)

Some project managers identified that those risks that were easy to process were those that may not have an actual impact on the project outcome and that softer behaviour related risks should not be neglected:

"The other issue was putting these risks into words, because they're often soft risks - the human factor. It is obviously easier to describe something technical. If I say, 'OK, the lorry doesn't arrive. What do I do then? I'll send another lorry', I 
can put that into words and come up with this or that measure. It's a simple process.” (Interviewee 1)

These examples show that project mangers focus on specific topics (e.g. on technical risk) but declare other topics are irrelevant. Nevertheless, what causes untopicality in project management and why do project managers declare risks outside their scope of project risk management? This study seems to indicate that first, that project managers accept that information that is easiest to process (perceived ease of risk management) and not necessarily that which may be most critical (perceived usefulness of risk management). A tame problem [30] receives more attention than wicked problem because it

- has a relatively well-defined and stable problem statement.

- has a definite stopping point, i.e. we know when the solution or a solution is reached.

- has a solution which can be objectively evaluated as being right or wrong.

- belongs to a class of similar problems which can be solved in a similar manner.

- has solutions which can be tried and abandoned.

Project managers are increasingly faced with problems of organised complexity, clusters of interrelated or interdependent problems, or systems of problems. Problems such as these, that cannot be solved in relative isolation from one another are messes. Project managers sort out messes through systems methods and modelling, focusing on processes and interdisciplinary approaches. Rather than simply breaking things down into parts and fixing components, project managers examine the patterns of interactions among parts, focusing on redundancy or irrelevance. Short [31] suggests: "All too often such measures rest upon what can easily be counted, rather than on what is meaningful 
to those who are at risk, ...”. Those risks that attract more attention than others may be "unusually visible, sensational, and easy to imagine" [32]. Rothstein [33] mentions in another context, that risk actors tended to focus on the better known and readilyresolvable risks, obvious risks or these being perceived as legitimate. Hence, the problem of wicked messes persists because managers continue to believe that there are such things as unilateral causation and independent and dependent variables.

\section{Undecidability}

Unlike topicality, the salient characteristic of undecidability is the lack of agreement on risks, expressed by one interviewee :

"We couldn't come to any opinion." (Interviewee 5)

In some projects, project managers failed to agree on possible threats to the project outcome, the likelihood that they would materialise and the appropriate response to mitigate the risk. Reason for the lack of agreement was the degree of criticality attributed to the risk. Risks that were not affected by third parties in a project were considered less critical than those directly affecting oneself:

"In terms there are certain risks which they do not regard as high risk which we would regard as being high risk. At the end of the day, it was our company's name on the telephone that was put on the customer's desk so any issue about the quality would directly affect us. It was not the partner's name so there was a certain issue like closeness to the product which made us much more sensitive to any potential issue that may come up and may be perceived to be a quality issue with the technology. We thought that partner was less sensitive to that kind of issue.” (Interviewee 10) 
The degree of undecidability or the inability to designate a risk as 'true' or 'false' was also influenced by the notion of 'hidden agendas' or undisclosed conflicting objectives between the project stakeholders.

"There was a large element of mistrust in this project. We had multiple consultancies operating in the one consortium. Some of the consultancies were natural competitors outside of this consortium and therefore within the consortium there was a lot of mistrust. As a result, the client had a degree of mistrust with regard to the various hidden agendas that might have been operating within that consortium." (Interviewee 13)

The lack of decidability on whether the message of risk is considered to be reliable, legitimate, fair or the deliverer of the message to be open and forthcoming, consistent honest, caring, concerned and competent [34], as well as the lack of ex-post decision control at the ex-ante stage of predicting risks and planning responses to risk is likely to lead to a 'relative credibility' of risks. This means that risk actors may perceive the risk's 'true' value differently. Among the interviewees who mentioned this, on their projects no consensus was achieved among stakeholders about the credibility of risks. The lack of consensus between risk actors' perceptions of risk relates to disbelief or a lack of faith in the message (risk) or the source of the message (person who produces the risk) $[20,35,36]$; it is a question of trust [37].

Trust appears to be the root cause of risk conflicts [38] and disagreements about risk's true nature. The problem of mistrust is addressed by Ritchie and Marshall [39] who argue: "There is a natural tendency to define a problem in such a way that the analytical results are valid and credible. ..., hazards which can be evaluated with confidence have been given comparatively more attention than other hazards". Hence, the disbelief in risk by risk actors or the disbelief in the source of risk is likely to relate to the risk 
actors' agreement on the management of risks that are clearer [40], more obvious and controllable [41] or easier to measure [42]. The sometimes conflicting relative credibility of risk estimates perceived by stakeholders tended to lead to lack of cooperation.

\section{Taboo}

Some interviewees described risk as a taboo. Because it would entail the disclosure of inconvenient information to project stakeholders, some risks were ignored. Taboos were already considered beyond the pale at the bidding stage of the project:

“... anyway, we had to go through a tendering process at the start of the project and, during this process, we presented ourselves in such a way that we would seem as reasonable and competent as possible. And problems and risks don't go down so well. We wanted to come across as people who could get the project under way and complete it. The first aim was to win the tender, no matter what the cost. In this sense, we had a somewhat unrealistic schedule.” (Interviewee 5) "I think only to a limited extent, as we would probably have identified risks, but they could never have been brought to the client's attention, because the priority was simply the successful completion of the project." (Interviewee 6)

"Not just unnerve them, but also lose the project, because there was very strong competition from other providers." (Interviewee 6)

As a result, in order to be viewed by stakeholders as competent as possible to deliver the desired project outcome, project mangers sought to avoid being perceived as entities who predicted calamity at every opportunity:

"I didn't want to be the doomsayer in the euphoric preliminary phase." (Interviewee 5) 
One way to reduce anxiety among stakeholders, that may arise through confronting them with uncertainties with possible negative consequences, is to deliberately ignore risks [43]. This choice of denial to or by stakeholders lies in the "freedom to choose whether or not to expose oneself (and others) to the dangers which lie in the activity (of risk management)" [44]. This would lead to the benefit of stakeholders (and by this we particularly mean project owners or sponsors) not being confronted with uncertainty. As a result of this apparent benefit (having to deal with the "fear of the unknown" [45]) individuals tend to be unwilling to manage risks [46]. Their unwillingness relates to the temptation to give people the answers they want to hear, and the answers are apparent certainty or a perception of a safe and predictable world [32, 43]. Because stakeholders may perceive risk (management) to be a gloomy and negative affair [15] or because stakeholders are more concerned with the exposure to potential adverse external opinion of failure than with the possible impact of uncertainties on the project [47] they downgrade their actual perceived risk to a desired external accepted level of risk [48] that can be "safely" engaged through risk management without the side effects of "dread". Thus, in so far as risks that may have an influence on the project outcome are suppressed, they are not managed for the sake of avoiding discomfort among stakeholders.

\section{Suspension of belief}

The previous types of irrelevance are in line with Smithson's [1] taxonomy of irrelevance. This study provides a detailed consideration of their manifestation in the context of project risk management. However, a further type of irrelevance emerged. This type does not refer to a double or dubious 'message' (undecidability), or information that is perceived as inconvenient (taboo), or to information that stakeholders deem 'out-of-scope' (untopicality). Rather, this was where risk-related 
information was regarded as being 'useless' because it did not have an immediate effect on the project. This was brought up by a number of interviewees, for example:

"In this particular environment, it was one that was used to "flying by the seats of its pants" and managing issues and crisis as they arrived rather than actually taking the time and stand back and look ahead and say "What can we do to prevent that?"." (Interviewee 5)

"In that particular organisation, once a risk had transpired it was all hands to the pump and they did what needed doing. That was the culture of the organisation to fire fight and run by crisis management." (Interviewee 14)

Hence, the project managers distanced themselves from this type of information because the perception was that they were dealing with some kind of 'fiction'. They did not want to expend resources on dealing with anything other than 'facts':

$\ldots$ if it did [risk materialised], we could get round it somehow (Interviewee 1)

Whereas on the one hand, some stakeholders' preference lies in identifying, analysing and responding in advance, other stakeholders appear to wait until risk resolves itself [49] and to react to actual materialising risks. Smallman [50] summarises the apparent emphasis of risk actors on reactive risk management: "It is hardly surprising that reactive risk management is dominant at the present time; it is, apparently, more certain and easier to manage and cost than the holistic approach." Their preference may lie in saving costs and time by reducing the scope of risk management rather than trying to manage all possible risks with the purpose of reducing the possibility of adverse consequences on the project objectives of cost, scope and time [51].

Executing actions to mitigate risks requires the commitment of resources, such as time and money. Resources are committed in advance to respond to risks that are not certain to occur but the client/owner or sponsor may be unwilling to spend money and energy 
on a management process without knowing it has definite benefits [23]. Raz and Michael [3] mention: "One of the reasons we included this part is that we met many project managers who claimed that risk management was an unnecessary activity, and that the resources it required could be put to better use elsewhere in the project." As a consequence, referring to the concept off 'satisficing' [52], project managers tended to meet the criteria for adequacy, rather than to identify the optimal solution. Information was not deemed pertinent because what can be done now to resolve a fictional problem is considered to require greater resources than doing something about facts. Possible explanations for 'satisficing' maybe a myopic propensity towards project efficiency. Project managers are nonchalant about risk related information because although the costs of taking actions to manage 'fictional' risk are immediately visible, the effect of threats that may or may not impact the project outcome is not.

As a working definition, this new project management related type of irrelevance is described as the act of suspending one's belief in risk related information and refers to placing such information at a lower order. This type of irrelevance is different to undecidability. If we assume that knowledge claims about a risk remain intact, that is to say, risk actors share a common belief that a risk is 'true', claims are still suspended because the utility (e.g. defined by cost, time, comfort, convenience, habits etc.) to do something about it now is perceived to be lower than the utility to deal with information once it is confirmed by 'real' events.

\section{Irrelevance and perceived effectiveness of project risk management}

We have identified four types of irrelevance (as a subset of ignorance) that have impacts of the management of risks in projects. Three could be correlated to Smithson's [1] taxonomy and to these we added 'suspension of belief'. We found that they were present in many of the projects mentioned by the interviewees and that, in some cases, the interviewees had experienced several types of irrelevance on the same project. 
However, we also wanted to examine the impact of irrelevance on the effectiveness of project risk management. 
Table 4 presents data on the perceived effectiveness of management activity at six stages in the risk management process. We have used a code to indicate the nature of the effect and then indicated the types of irrelevance that were identified in each case. 
Table 4: Summed indices - perceived effectiveness of project risk management stages and related types of error and irrelevance

\begin{tabular}{|c|c|c|c|c|c|c|c|c|}
\hline Project & Planning & $\begin{array}{l}\text { Identify } \\
\text { Threat }\end{array}$ & $\begin{array}{l}\text { Attach } \\
\text { Probability }\end{array}$ & $\begin{array}{l}\text { Determine } \\
\text { Effects }\end{array}$ & $\begin{array}{l}\text { Evaluate } \\
\text { Response }\end{array}$ & $\begin{array}{l}\text { Determine } \\
\text { Response } \\
\text { Owner }\end{array}$ & $\begin{array}{l}\text { Execute } \\
\text { Actions }\end{array}$ & Irrelevance \\
\hline Interviewee1 & $\mathrm{NA}$ & $\mathrm{x}$ & & $\uparrow$ & $\uparrow$ & $\mathrm{x}$ & $\mathrm{X}$ & S, UT, UD \\
\hline Interviewee 2 & NA & $\mathrm{x}$ & $\mathrm{x}$ & $\uparrow$ & NA & NA & $\uparrow$ & UT, UD, T \\
\hline Interviewee 3 & $\mathrm{NA}$ & $\uparrow$ & $\uparrow$ & NA & $\uparrow$ & $\uparrow$ & & \\
\hline Interviewee 4 & NA & $\uparrow$ & $\uparrow$ & & $\uparrow$ & $\uparrow$ & $\mathrm{x}$ & \\
\hline Interviewee 5 & $X-n$ & $X-n$ & $X-n$ & $X-n$ & $X-n$ & $X-n$ & $X-n$ & $\mathrm{~S}$ \\
\hline Interviewee 6 & $X-n$ & $X-n$ & $X-n$ & $X-n$ & $X-n$ & $X-n$ & $X-n$ & $\mathrm{~T}$ \\
\hline Interviewee 7 & & $\uparrow$ & $\mathrm{x}$ & & & NA & & UD \\
\hline Interviewee 8 & $\uparrow$ & $\mathrm{X}$ & $\mathrm{x}$ & $\mathrm{X}$ & $\mathrm{x}$ & $\mathrm{x}$ & $\mathrm{x}$ & UD, UT \\
\hline Interviewee 9 & $\uparrow$ & $\mathrm{x}$ & & $\mathrm{X}$ & $\uparrow$ & $\mathrm{x}$ & $\uparrow$ & T, UT \\
\hline Interviewee 10 & $\uparrow$ & $\uparrow$ & $\mathrm{x}$ & $\uparrow$ & $\uparrow$ & $\mathrm{x}$ & & UD, UT \\
\hline Interviewee 11 & $\uparrow$ & $\mathrm{X}$ & $\mathrm{x}$ & $\mathrm{X}$ & $\mathrm{X}$ & NA & $\mathrm{x}$ & $\mathrm{S}$ \\
\hline Interviewee 12 & $\uparrow$ & $\mathrm{x}$ & $\mathrm{x}$ & $\mathrm{x}$ & & & $\mathrm{x}$ & $\mathrm{S}$ \\
\hline Interviewee 13 & NA & $\mathrm{X}$ & $\mathrm{x}$ & NA & $\mathrm{x}$ & $\mathrm{x}$ & $\mathrm{x}$ & UD, UT, T \\
\hline Interviewee 14 & NA & $\uparrow$ & $\mathrm{X}$ & NA & NA & $\mathrm{X}$ & $\mathrm{X}$ & $\mathrm{S}$ \\
\hline Interviewee 15 & & & $\uparrow$ & NA & & & $\uparrow$ & \\
\hline Interviewee 16 & $\mathrm{x}$ & & $\uparrow$ & $\mathrm{x}$ & $\uparrow$ & $\mathrm{x}$ & NA & UT \\
\hline Interviewee 17 & NA & $\mathrm{x}$ & NA & NA & NA & $\mathrm{x}$ & $\mathrm{x}$ & $\mathrm{s}$ \\
\hline Interviewee 18 & $X-n$ & $X-n$ & $X-n$ & $X-n$ & $X-n$ & $X-n$ & $X-n$ & $\mathrm{~T}$ \\
\hline \multicolumn{9}{|c|}{ Perceived effectiveness: } \\
\hline \multicolumn{9}{|l|}{$\uparrow=$ Effective } \\
\hline \multicolumn{9}{|c|}{$X=$ Not effective } \\
\hline \multicolumn{9}{|c|}{$X-n=$ no effectiveness - No project risk management applied } \\
\hline \multicolumn{9}{|c|}{ NA = Data not available } \\
\hline \multicolumn{9}{|c|}{ Blank $=$ No unambiguous effectiveness cited } \\
\hline \multicolumn{9}{|l|}{ Irrelevance: } \\
\hline \multicolumn{9}{|c|}{ UT- Untopicality } \\
\hline \multicolumn{9}{|c|}{ S - Suspension (Cost/Time) } \\
\hline \multicolumn{9}{|l|}{ T - Taboo } \\
\hline UD - Undecide & blity & & & & & & & \\
\hline
\end{tabular}

Without ignoring the influence of error on the perceived effectiveness of project risk management, irrelevance seemed to adversely influence the process of the management of risk on the projects our interviewees mentioned. In particular, the inability to decide whether risk related information was true or false was found to be of concern when analysing probabilities. Meanwhile, taboos seemed to have an impact on the phase of planning the risk management process and identifying threats. Elsewhere, untopicality became a problem at the stage of defining a response owner. We found suspension of belief manifested itself as a type of cost/time subordination, which had an impact right 
at the outset in deciding whether or not to apply a formal risk management process. Once, the decision was taken subordination reduced the capability of a project manager to define response alternatives and to ultimately execute actions. Overall, due to the influence of irrelevance at various stages of the project risk management process, the capability of some project managers to manage risk seemed to be reduced to a 'tickbox' exercise with little significance on the actual mitigation of risk:

“... people would see it merely as putting a tick in the box. Yes, we are doing a project risk assessment.” (Interviewee 13)

“...it becomes an administrative process and as long people feel there is a risk register somewhere and lip services paid to in on a reasonably frequent basis that they are managing risk.” (Interviewee 17)

Risk related information is processed because project manager are supposed to follow the formal procedures despite a feeling of powerlessness and alienation. In the extreme, fatalistic tendencies resulted in pure defiance and a resistance to apply any form of proactive management of risk (in, for example, the cases of interviewees 5, 6 and 18).

\section{The management of relevance}

Although ignorance, in the form of irrelevance, may not arise in all projects but may potentially arise in any given project, this study has highlighted how established types of irrelevance manifest themselves in project management, together with another category which we called suspension of belief. Coping with ignorance requires responding to errors and irrelevancies. This study has allowed an extended understanding of ignorance in project management so that strategies can be implemented to help optimise project risk management process. This entails the management of relevance. 
Whereas error requires clarification, exactitude and rectification through enquiry, irrelevance in project risk management can be overcome through the management of relevance that defines the extent of information exclusion. The overall aim of the management of relevance is limiting the exclusion of risk and ultimately to reduce fatalistic tendencies in project risk management. Barriers of untopicaility, undecidability, taboo and suspension of belief have to be overcome. From the data, it would appear that when addressing risk information, managers are most likely to consider topicality first, then truthfulness and finally utility. Against these concepts we have mapped the four categories of irrelevance, as shown in Figure 2.

Figure 2: A multi stage process of relevance evaluation [30]

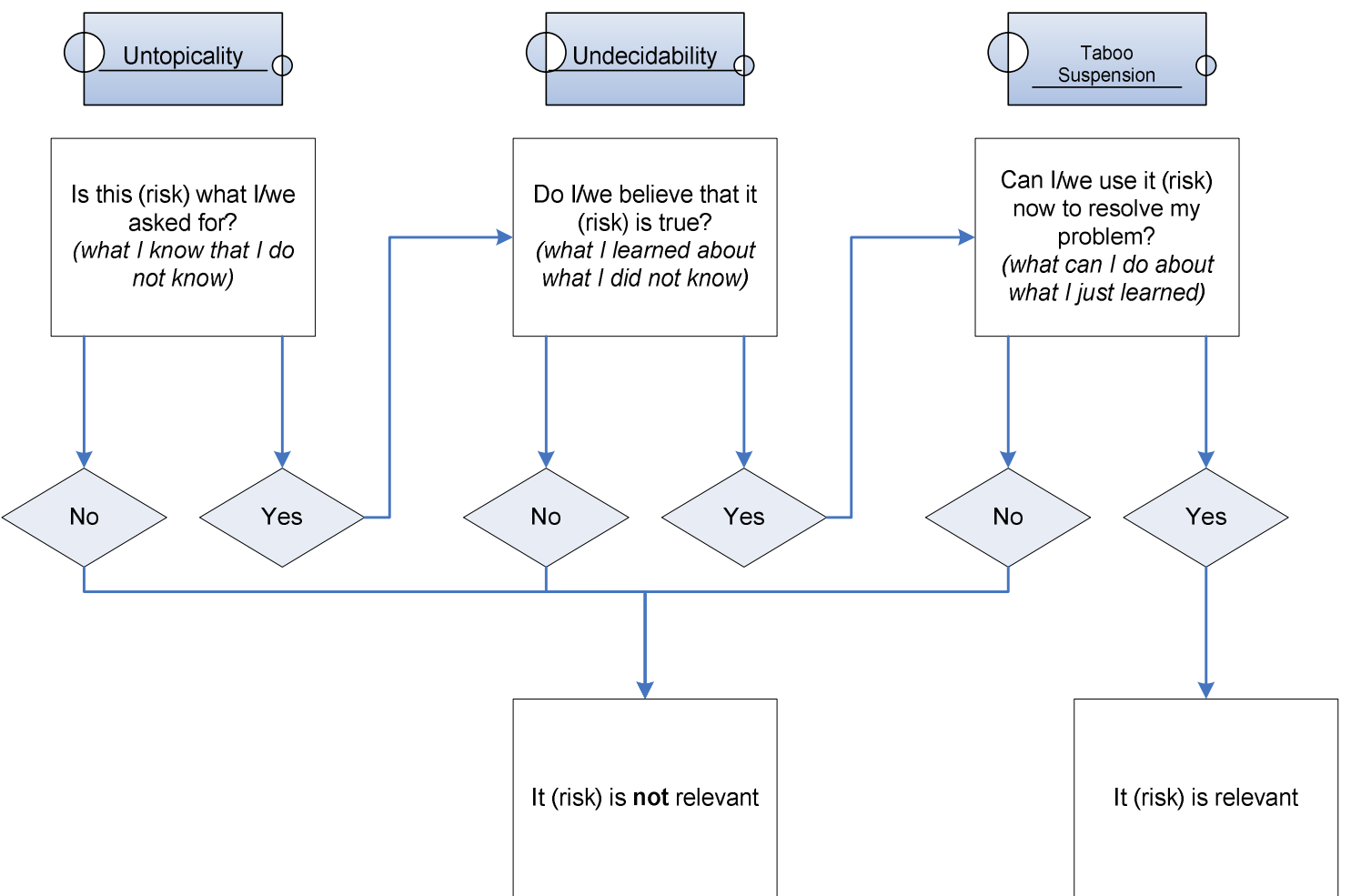

First, untopicality requires stakeholders to define a common scope of risk management.

This may include the mindfulness of being able to only process tame risks and that wicked messes are to be excluded. Defining a common nominator for what type of threats stakeholders are looking for prevents risks being 'off-topic' and therefore irrelevant. 
Once risks have been defined as 'on topic' and a common view as emerged of what scope is acceptable, trust has to been built up that allows an agreement on what risks are considered 'true' and which 'false'. If a common belief in the nature of project risk is not gained, it may be decided to gain further data in order to engage establish why risks are seen as incomplete and irrelevant.

The final stage relates to the evaluation of utility. Considering time and cost constraints, project managers evaluate the usefulness of risk information. Preferences to mitigate risk, to prevent anxiety by disclosing damaging information to oneself or other stakeholders and the propensity towards myopic efficiency are prioritised and ultimately determine the degree of relevance of project risks in IT projects regardless of their objective degree of error.

The management of relevance proposes a determination of relevance and to which extent risk related information is excluded in a world characterised by uncertain boundaries. Almost every risk may be of interest, but the management of risk requires information about threat, probability and response. Current project risk management processes do not propose any prescriptive process to define the relevance of risk apart from a ranking of risks according to their threat and their likelihood of occurrence. The discovered four principles and their management may guide a project manager to first, to create awareness about irrelevance and second, how to overcome it.

There are two major limitations of this study. First, the sample of the second phase of exploration which included a narrow segment of IT project managers. Second, limited generalisabilty arises through the use of subjective data. In particular, the IT project manager's reality which has been investigated in this study may not be transferable to other individuals. As a consequence, tendencies which have emerged and been explored cannot be generalised beyond the chosen sample cluster. As a result, it may be 
worthwhile to determine whether the same types of irrelevance prevail in other types of projects and in what form.

\section{CONCLUSIONS}

Project risk management with its assumptions of 'hyper rationality' excludes many aspects of managerial behaviour. Organisations such as the Project Management Institute or the Association of Project Management claim that through the identification, analysis and response to risk, project managers can achieve planned project outcomes.

Little research has been undertaken to ascertain whether project managers involved in risk management activity perceive the self-evidently correct processes and procedures they implement to be effective. There seems to be far more literature offering prescriptions to project managers on how to manage risk in project rather than assess the relative effectiveness of those prescriptions. Neither the shortcomings of current project risk management processes nor options to change and/or expand those best practice standards to include behavioural aspects of irrelevance have received much attention in literature so far. As long as no evidence is produced, whether project risk management actually helps project managers from their point of view ('doing things right'), the acceptance of best practice project risk management standards is at stake ('doing the right things').

The findings of this study show that in some projects, project risk management is conditioned by deliberate ignorance of project managers. The factors of untopicality, undecidabilty and utility of risk related information characterised by taboos and suspension of belief appear to demote risk management to an administrative exercise having no or only little impact on the project outcome. Indeed, if irrelevance remains unattended by project managers, project risk management might turn out to be not only ineffective but also counterproductive. 
The research undertaken involved projects specifically from the IT industry and, as such, the extent to which the findings are more generally applicable to, say, engineering, construction or change projects is open to question. The specific nature of the project (industrial sector, complexity, size, etc.[53]) is less likely to be an issue. Rather, the generalisability would, in this case, be limited by the character of the social conditions found in different project types. We would argue that it is the social conditions (such as organizational and, maybe, national culture) that would govern the response of project actors to the way they regard the relevance of project risk information. The question then becomes one of whether projects from, for example, different industries, or projects of differing complexities, have different cultures. Future research could examine this question as well as seek to validate the categories of irrelevance across a wider sample of projects. 


\section{REFERENCES}

[1] M. Smithson, Ignorance and Uncertainty. New York: Springer-Verlag, 1989,

[2] Project Management Institute, A Guide to the Project Management Body of Knowledge. ,Third ed.Pennsylvania: Project Management Institute, 2004,

[3] T. Raz and E. Michael, "Use and benefit of tools for project management," International Journal of Project Management, vol. 19, pp. 9-17, 2001.

[4] S. Pender, "Managing incomplete knowledge: Why risk management is not sufficient," International Journal of Project Management, vol. 19, pp. 79-87, 2001.

[5] British Standards Institution, "Project management - part 3: Guide to the management of business related project risk," British Standards Institute, London, 2000.

[6] Office of Government Commerce, "Management of risk: Guidance for practitioners;" The Stationary Office, 2007.

[7] Association for Project Management, Project Management Body of Knowledge. London: Association for Project Management, 2005,

[8] I. Ben-David and T. Raz, "An integrated approach for risk response development in project planning," Journal of the Operational Research Society, vol. 52, pp. 14-25, 2001.

[9] J. Raftery, Risk Analysis in Project Management. London: Chapman \& Hall, 1994,

[10] T. M. Williams, "Assessing and moving on from the dominant project management discourse in the light of project overruns." IEEE Transactions on Engineering Management, vol. 52, pp. 497-508, 2005.

[11] A. Tversky and D. Kahneman, "Advances in prospect theory: Cumulative representation of uncertainty," Journal of Risk and Uncertainty, vol. 5, pp. 297-323, 1992.

[12] D. Borge, The Book of Risk. New York: John Wiley \& Sons, 2001,

[13] K. J. Arrow, "Behaviour under uncertainty and its implications for policy," in Foundations of Utility and Risk Theory with Applications B. P. Stigum and F. Wenstop, Eds. Dordrecht: D. Reidel Publishing Company, 1983, pp. 19-32.

[14] H. J. Einhorn and R. M. Hogarth, "Decision making under ambiguity," Journal of Business, vol. 59, pp. 225-250, 1986.

[15] J. M. Weber, S. Kopelman and D. M. Messick, "A Conceptual Review of Decision Making in Social Dilemmas: Applying a Logic of Appropriateness," Personality \& Social Psychology Review (Lawrence Erlbaum Associates), vol. 8, pp. 281-307, 2004.

[16] R. D. Congleton, "In Defense of Ignorance: on the Significance of a Neglected Form of Incomplete Information," Eastern Economic Journal, vol. 27, pp. 391, Fall. 2001.

[17] K. R. Ehrich and J. R. Irwin, "Wilful Ignorance in the Request for Product Attribute Information," Journal of Marketing Research (JMR), vol. 42, pp. 266-277, 08. 2005.

[18] H. Greisdorf, "Relevance thresholds: a multi-stage predictive model of how users evaluate information," Information Processing \& Management, vol. 39, pp. 403, 05. 2003. 
[19] P. Slovic, M. L. Finucane, E. Peters and D. G. MacGregor, "Risk as analysis and risk as feelings," Decision Research, Eugene, 2002.

[20] H. Margolis, Dealing with Risk. London: The University of Chicago Press, 2003,

[21] M. Douglas, Risk Acceptability According to Social Sciences. Padstow: T J Press, 1986,

[22] S. Frosdick, "The techniques of risk analysis are insufficient in themselves," Disaster Prevention and Management, vol. 6, pp. 165-177, 1997.

[23] P. S. Royer, "Risk management: The undiscovered dimension of project management," Project Management Journal, vol. 31, pp. 6-13, 2000.

[24] M. Ramgopal, "Project uncertainty management," Cost Engineering, vol. 45, pp. 21-24, 2003.

[25] R. P. Larrick and J. B. Soll, "Intuitions About Combining Opinions: Misappreciation of the Averaging Principle," Management Science, vol. 52, pp. 111-127, 01. 2006.

[26] D. H.T. Walker, G. Aranda-Mena, M. Arlt and J. Stark, "E-Business and Project Procurement" in D. H. T. Walker and S. Rowlinson (eds.) Procurement Systems: A Crossindustry Project Management Perspective, London: Taylor-Francis, 2007.

[27] N. J. Fox, "Postmodern reflections on 'risk', 'hazard' and life choices" in D. Lupton (ed.) Risk and sociocultural theory : new directions and perspectives, Cambridge: Cambridge University Press, 1999

[28] R. E. Stake, The Art of Case Study Research. London: SAGE Publications Ltd., 1995,

[29] C. Robson, Real World Research: A Resource for Social Scientists and Practitioner Researchers. ,2nd ed. London: Blackwell Publishers, 2002,

[30] R. Holt, "Risk management: The talking cure," Organization, vol. 11, pp. 251-270, 2004.

[31] J. F. Short, "On defining, describing and explaining elephants (and reactions to them): Hazards, disasters, and risk analysis," International Journal of Mass Emergencies and Disasters, vol. 7, pp. 397-418, 1989.

[32] B. Fischhoff, S. Lichtenstein, P. Slovic, S. L. Derby and R. L. Keeney, Acceptable Risk. Cambridge: Cambridge University Press, 1981,

[33] H. Rothstein, "Neglected risk regulation: The institutional attenuation phenomenon," Centre for analysis of risk and regulation, London, Tech. Rep. Discussion paper no: 7, October 2002, 2002.

[34] L. Warg and M. Wester-Herber, "Restoring trust by participation: A comment based on social judgement theory," in Risk Analysis: Facing the New Millennium, 1999,

[35] W. Poortinga and N. F. Pidgeon, "Exploring the dimensionality of trust in risk regulation," Risk Analysis, vol. 23, pp. 961-972, 2003.

[36] B. H. Sheppard and D. M. Sherman, "The grammars of trust: A model and general implications," Academy of Management Review, vol. 23, pp. 422-437, 1998.

[37] A. Kadefors, "Trust in project relationships - inside the black box," International Journal of Project Management, vol. 22, pp. 175-182, 2004. 
[38] P. Slovic, "Perceived risk, trust, and democracy," Risk Analysis, vol. 13, pp. 675-682, 1993.

[39] B. Ritchie and D. Marshall, Business Risk Management. London: Chapman \& Hall, 1993,

[40] C. Heath and A. Tversky, "Preference and belief: Ambiguity and competence in choice under uncertainty," Journal of Risk and Uncertainty, vol. 4, pp. 5-28, 1991.

[41] A. Michalsen, "Risk assessment and perception," Injury Control and Safety Promotion, vol. 10, pp. 201-204, 2003.

[42] W. D. Rowe, "Understanding uncertainty," Risk Analysis, vol. 14, pp. 743-750, 1994.

[43] P. Slovic, "Perception of risk," Science, vol. 23, pp. 280-285, 1987.

[44] A. R. Hale, "Subjective risk," in Risk and Decisions W. T. Singleton and J. Hovden, Eds. Chichester: John Wiley \& Sons, 1987, pp. 67-85.

[45] D. Ghosh and M. R. Ray, "Risk, ambiguity, and decision choice: Some additional evidence," Decision Sciences, vol. 28, pp. 81-104, 1997.

[46] M. P. White, S. Pahl, M. Buehner and A. Haye, "Trust in risky messages: The role of prior attitudes," Risk Analysis, vol. 23, pp. 717-726, 2003.

[47] D. Parker and A. Mobey, "Perceptions in risk evaluation for project management," in EurOMA - POMS Conference, 2003, pp. 443-453.

[48] G. E. Machlis and E. A. Rosa, "Desired risk: Broadening the social amplification of risk framework," Risk Analysis, vol. 10, pp. 161-168, 1990.

[49] B. Yang, N. D. Burns and C. J. Backhouse, "Management of uncertainty through postponement," International Journal of Production Research, vol. 42, pp. 1049-1064, 2004.

[50] C. Smallman, "Challenging the orthodoxy in risk management," Safety Science, vol. 22, pp. 245-262, 1996.

[51] F. Redmill, "Risk analysis - A subjective process," Engineering Management Journal, vol. April, pp. 91-96, 2002.

[52] H. A. Simon, "Theories of decision-making in economics and behavioral science." American Economic Review, vol. 59, pp. 253-- 283, 1979.

[53] L. Crawford, B. Hobbs and J.R. Turner, Project Categorization Systems: Aligning capability with strategy, Project Management Institute, Newton Square, PA, 2005. 